\title{
Health Problems in Survivors Exposed to Sulfur Mustard with Severe Respiratory Complications
}

\section{ART I C L E INF O}

\section{Article Type}

Descriptive Study

\section{Authors}

Soroush M.R. ${ }^{1} M D, M P H$

Akhavizadegan $\mathrm{H}^{2} M D$,

Mousavi B. ${ }^{* 3} M D, M P H$

\begin{abstract}
A B S T R A C T
Aims The complications of sulfur mustard (SM) in lungs, eyes, and skin of exposed survivors have already been studied. This study evaluates health problems of other than the usual affected organs in survivors with severe respiratory injuries.

Instruments \& Methods In this descriptive cross-sectional study, 292 chemical warfare veterans with severe pulmonary complications due to exposure to sulfur mustard were examined by two physicians in 2016. Health problems in the veterans were recorded and a clinical examination was performed. Data using SPSS software version 2016 and Chi-square test and Lambda correlation coefficient were analyzed.

Findings The most common problems of chemical warfare victims with severe pulmonary complications were related to musculoskeletal problems $92.1 \%$ (low back pain $68.8 \%$ ), neurological system 88.4\%(headache 78.1\%), auditory system 81.8\%(Hearing loss $62 \%$ ), gastrointestinal tract $78.1 \%$ (reflux $74.3 \%$ ), kidney and urinary tract $(65.1 \%$ ), cardiovascular (52.4\%), immune system disorders (43.4\%) and infertility $10.6 \%$. The mean systolic and diastolic blood pressure of the veterans were $121.1 \pm 14.7$ and $79.7 \pm 8.8 \mathrm{mmHg}$, respectively. Most of them were under treatment of respiratory corticosteroids (72.2\%) and oral corticosteroids (45\%). There were no significant relationships between gender, age, frequency of exposure to sulfur mustard, and the prevalence of physical complaints and musculoskeletal diseases, nervous system, gastrointestinal tract, cardiovascular system, and hearing loss ( $\mathrm{p}>0.05)$.

Conclusion The most important health problems were musculoskeletal, neurological, hearing loss, and gastrointestinal problems. Moreover, the rate of using corticosteroids was very high while the rate of Infertility was less prevalent than previous studies. These results will help investment policies aiming at considering future health promotion planning.
\end{abstract}

Keywords Sulfur Mustard; Chemical; Pulmonary Injury; Health; Disease
${ }^{1}$ Janbazan Medical and Engineering Research Center (JMERC), Tehran, Iran

${ }^{2}$ Urology Department, Sina hospital, Tehran University of Medical Sciences

${ }^{3}$ Prevention Department, Janbazan Medical and Engineering Research Center (JMERC), Tehran, Iran

\section{*Correspondence}

Address: Janbazan Medical and Engineering Research Center (JMERC), Tehran, Iran.

Phone: -

Fax: -

mousavi.b@gmail.com

\section{Article History}

Received: March 15, 2020

Accepted: May 14, 2020

ePublished: June 17, 2020

\section{I T A T I O N L I N K S}

[1] Chemical warfare agents: Toxicology ... [2] Human Costs of Iraq's chemical war against Iran; an ... [3] Mustard: A potential agent of chemical ... [4] Chemical warfare agents: Toxicity at low ... [5] Comparison of early and late toxic effects ... [6] Incidence of lung, eye, and skin lesions as late ... [7] The diversity of the effects of sulfur mustard ... [8] Long-term health status 20 years after ... [9] Long-term complications of sulphur mustard ... [10] Ocular effects of sulfur ... [11] Skin manifestations in sulfur mustard exposed victims ... [12] Delayed ocular complications of mustard ... [13] Long-term ocular complications of sulfur ... [14] Systemic and ocular complications of sulfur ... [15] The delayed ocular and pulmonary complications ... [16] Delayed ocular, pulmonary, and cutaneous complications ... [17] Urogenital history in veterans exposed to ... [18] Cutaneous and ocular late complications ... [19] Long-term complications of sulphur mustard ... [20] The clinical toxicology of sulfur ... [21] Delayed head and neck complications of sulphur ... [22] Symptoms in 18,495 Persian Gulf War veterans ... [23] Chemical warfare agents: Toxicity at low ... [24] Distal esophagitis in patients with mustard ... [25] Gulf War veterans' health: Medical evaluation ... [26] Myocardial perfusion abnormalities in chemical warfare ... [27] Reproductive function in men following exposure ... [28] Assessment of fertility among mustard-exposed ... 


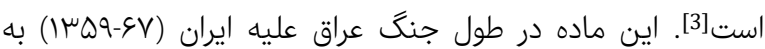

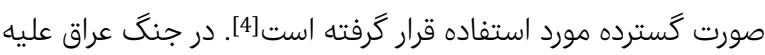

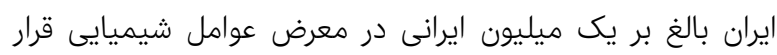

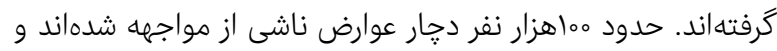

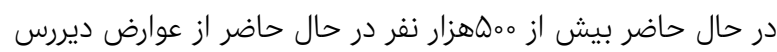

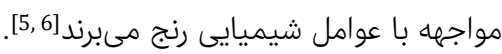

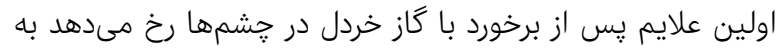

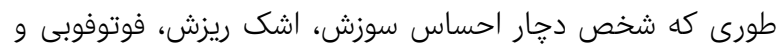

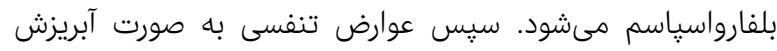

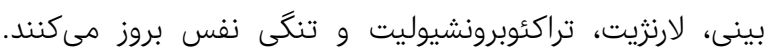

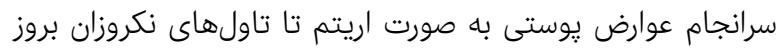

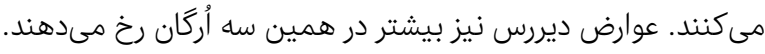

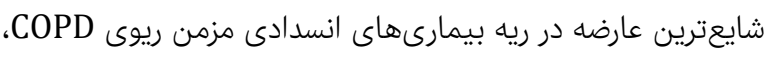

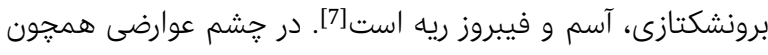

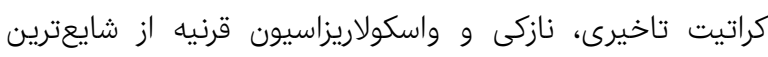

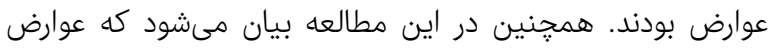

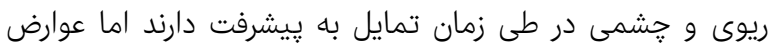

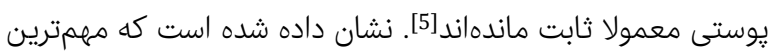

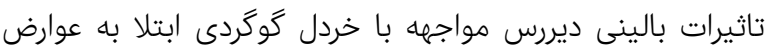

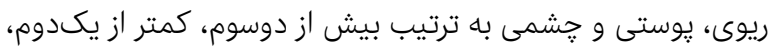

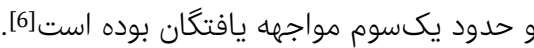

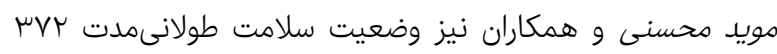

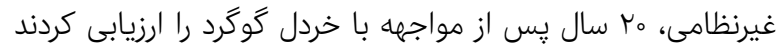

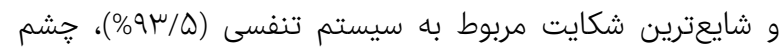

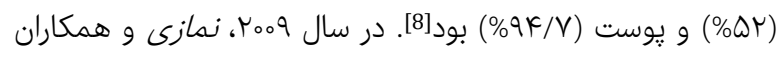

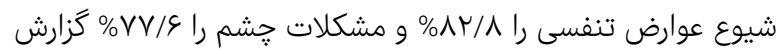

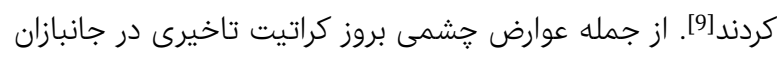

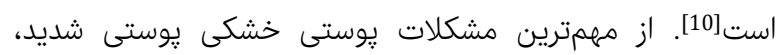

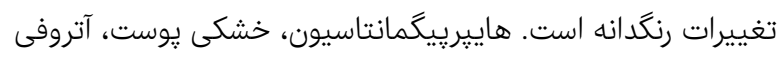

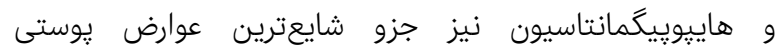

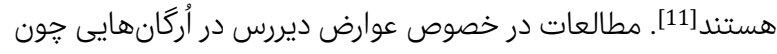

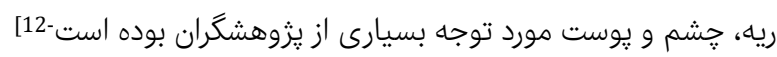

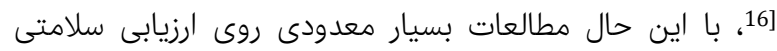

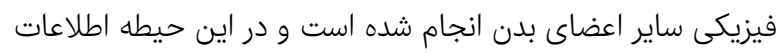
كم و محدودى به جاب رسيده است[17].

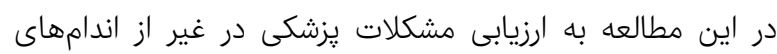

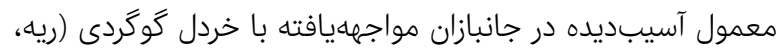

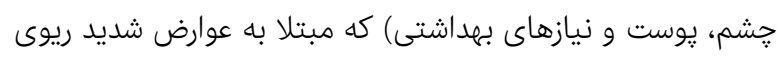

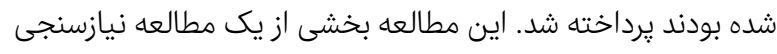

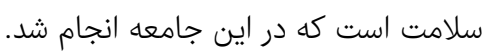

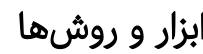

در اين مطالعه توصيفى-مقطعى، وضعيت سلامت جسمانى همها جانبازانى كه مبتلا به عوارض شديد ريوى در اثر مواجهه با خردل دوره rا، شماره r، بهار 99سا
مشكلات سلامت در جانبازان مبتلا به عوارض شديد ريه ناشى از مواجهه با خردل گوگردى مبلان

MD, MPH محمدرضا سروش

مركز تحقيقات مهندسى و علوم يֶرشكى جانبازان، تهران، ايران

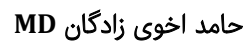
كَره ارولوزى، بيمارستان سينا, دانشكاه علوم يزشكى تهران، تهران، ايران

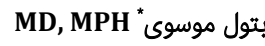
كروه بيشكَيرى، مركز تحقيقات مهندسى و علوم يزشكى جانبازان، تهران، ايران جكيده اهداف: عوارض ريوى يوستى و جشمى ناشى از مواجهه با خردل گَّرَدى در

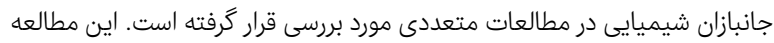

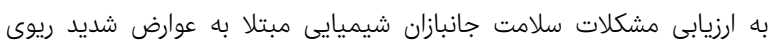

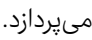

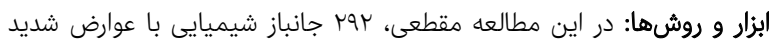

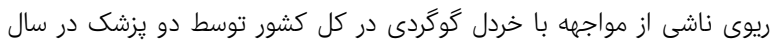

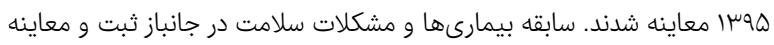

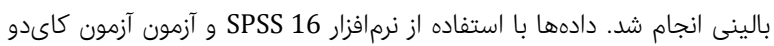

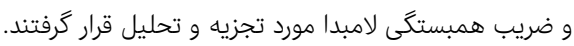

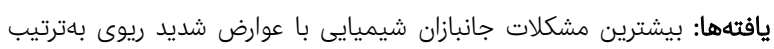

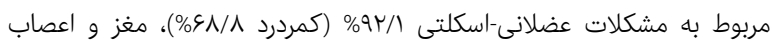

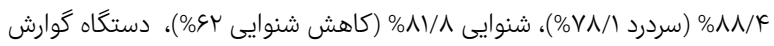

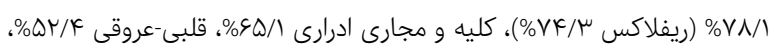

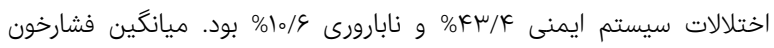

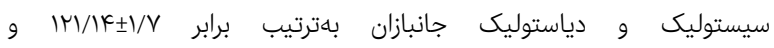

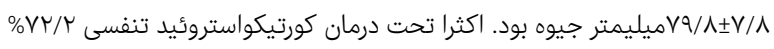

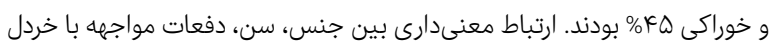

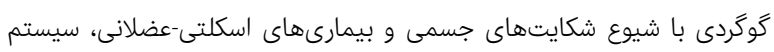

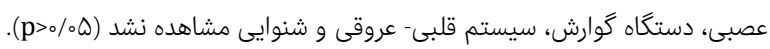

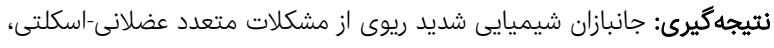

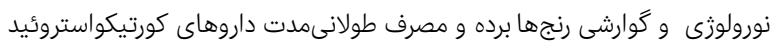

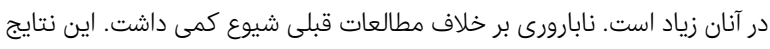

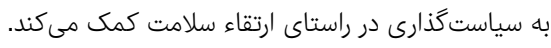

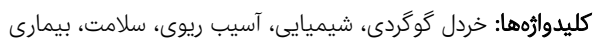

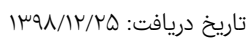

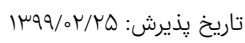

mousavi.b@gmail.com :نويسنده مسئول: تاريخ

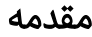

خردل گَوَردى عامل شيميايى تاولزا است كه از طريق يوست،

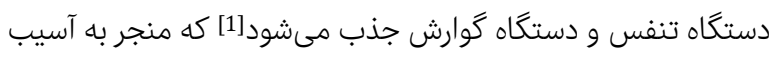

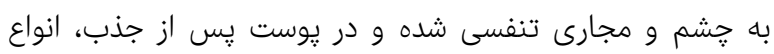

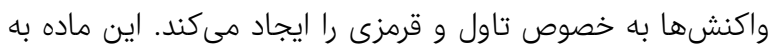
آرامى در آب تجزيه شده و تشكيل اسيدهيدروكلريك را را مى آدهدي.

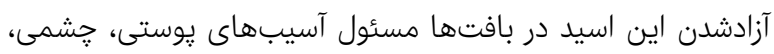

تنفسى و كَوارشى است] [2].

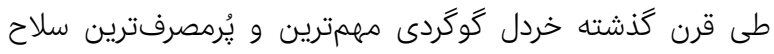
شيميايى بوده است كه در بيش از ما جنَّ مورد استفاده قرار كرفته 


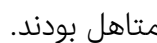

مشكلات سلامت جانبازان شيميايى شديد ريوى بله تفكيك ردان

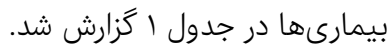

جدول () درصد شيوع مشكلات سلامت در جانبازان مواجههيافته با خردل گوگردى

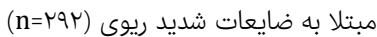

\begin{tabular}{|c|c|c|}
\hline درصد & تعداد & مشكلات سلامت \\
\hline $9 \% / 1$ & rदq & عضلانى-اسكلتى \\
\hline $9 / / \Lambda$ & rol & كمردرد \\
\hline$\Delta \Lambda / r$ & IV。 & درد مزمن مفاصل \\
\hline$M / Q$ & $\Delta F$ & يوكى استخوان \\
\hline$\Delta / 9$ & iv & ساير موارد \\
\hline$\Lambda N / \mathcal{K}$ & $r \Delta \Lambda$ & سيستم مغز و اعصاب \\
\hline VA/I & rra & سردرد مزمن \\
\hline$\varsigma_{1 / \mu}$ & IVq & سرگيجه \\
\hline$\mu / l$ & 9 & صرع \\
\hline $1 / V$ & Q & ميكرن \\
\hline$\circ / \mu$ & 1 & ساير \\
\hline$\wedge \mathrm{I} / \Lambda$ & $r \mu q$ & سيستم شنوايى \\
\hline sr & $|\wedge|$ & كاهش شنوايى \\
\hline$\Delta q / q$ & IVD & وزوز گوش \\
\hline$\circ / V$ & r & ساير \\
\hline VA/I & rra & دستكاه گوارش \\
\hline$V F / \mu$ & MIV & ريفلاكس معده به مرى \\
\hline$k / \Lambda$ & If & سندروم روده تحريكيذير \\
\hline $11 / \mu$ & 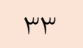 & كاستريت \\
\hline $1 / \circ$ & $\mu$ & ساير \\
\hline$V T / \mu$ & rII & دستگاه بارورى \\
\hline s1/9 & $1 \wedge$ & اختلال ميل جنسى \\
\hline $10 / 9$ & $\mu$ & 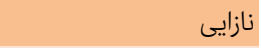 \\
\hline $9 \Delta / 1$ & 19. & كليه و مجارى ادرارى \\
\hline$I V / Q$ & Q1 & سنگهاى ادرارى \\
\hline N/\& & $r \Delta$ & عفونتهاى ادرارى مكرر \\
\hline$\circ / V$ & r & ي پِيلونفريت مكرر \\
\hline$\circ / V$ & r & نارسايى كليه \\
\hline$\mu / \Lambda$ & 11 & ساير موارد \\
\hline$\Delta r / \mathcal{F}$ & $1 Q \mu$ & سيستم قلبى-عروقى \\
\hline $\mathrm{kr} / \mathrm{A}$ & ira & درد قفسه سينه \\
\hline $19 / 9$ & $\Delta \wedge$ & فشارخون \\
\hline$\mu / k$ & 10 & سكته قلبى \\
\hline$r / 1$ & 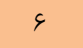 & نارسايى قلبى \\
\hline$\mu / k$ & 10 & ساير \\
\hline$k \psi / k$ & ITV & اختلالات سيستم ايمنى \\
\hline MY。 & $F Q$ & آلرزى غذايى \\
\hline$V / r$ & r & آلرزى دارويى \\
\hline$\wedge / 9$ & re & آلرزى فصلى \\
\hline $10 / 1$ & ks & ساير موارد \\
\hline
\end{tabular}

معاينه شكم در هسץ نفر (ه/A\%)، طبيعى بود، اما حساسيت

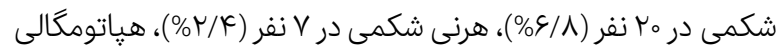

كَوَّردى در طول حملات شيميايى در جنَّ عراق عليه ايران قرار

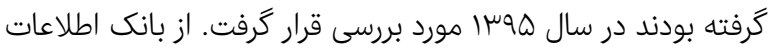
بنياد شهيد براى انتخاب نمونههاى مورد نظر در كل ايران استفاده

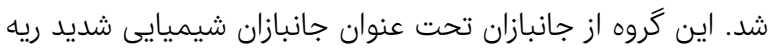

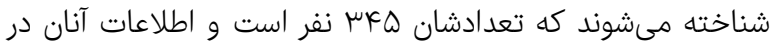

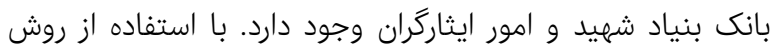

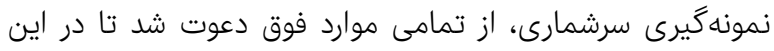

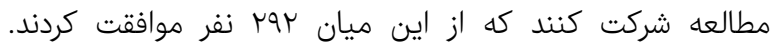

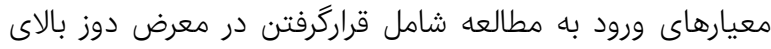

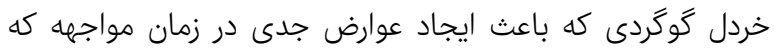
منجر به بسترىشدن مصدوم شيميايى و نياز به مراقبتهاى

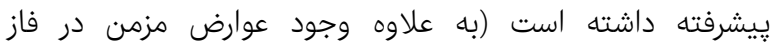
تاخيرى)[18]، بروز عوارض شديد ريوى ناشى از مواجها شيميايى خردل گوگردى با شاخصهاى Forced FEV1) (Forced Vital FVC كمتر از Expiratory Volume) كمتر از Capacity)

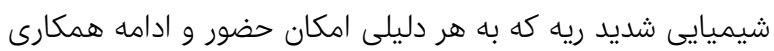

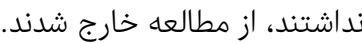

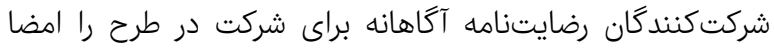

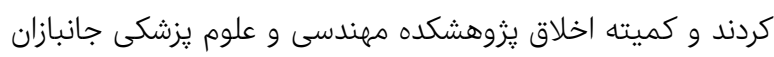
نيز اين طرح را با كد 87-E-P-102 تاييد كرد. ابتدا اطلاعات جمعيتشناسى شامل سن، جنس، وضعيت تاهل، دفعات مواجها

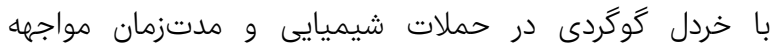
جمعآورى شد. سيس جانبازان توسط يزشك معاينه شدند. سابقاته

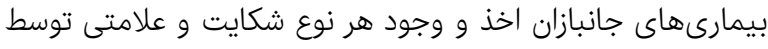

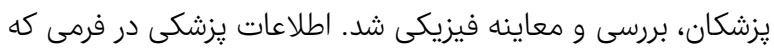

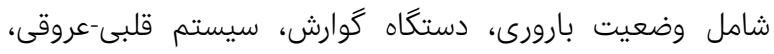
مشكلات شنوايى، سيستم اعصاب مركزى و ستون مهرونها و وسكاه

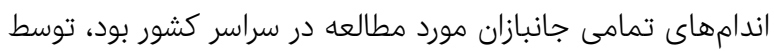

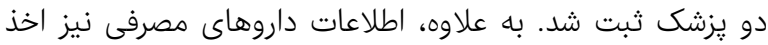

ش

دادهها با استفاده از نرمافزار 16 SPSS مورد تجزيه و تحليل قرار

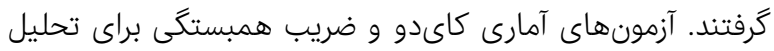

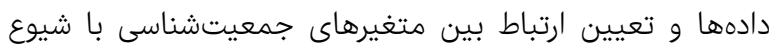

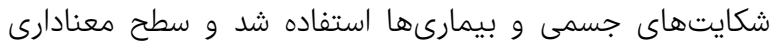
كمتر از ه٪ در نظر گرفته شده است.

يافتهها

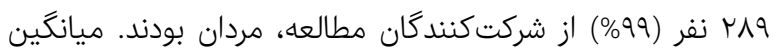
سن آنها $/$ س/

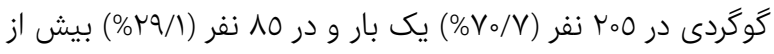

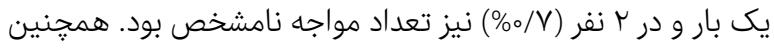

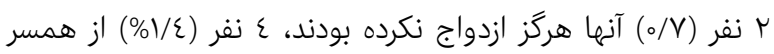
خود جدا شده بودند يا اينكه همسر فوت كرده بود و باقى (9/9V\%) 


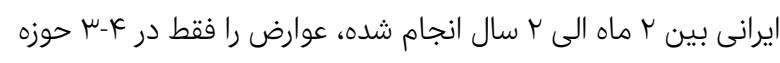

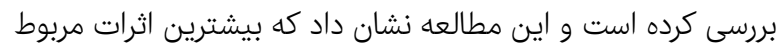

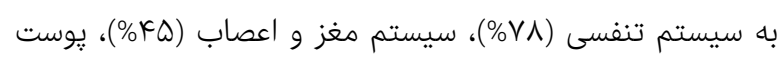

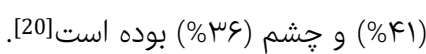
شيوع بيمارىهاى حاد و مزمن در مواجهايافتكان در زمان حملات

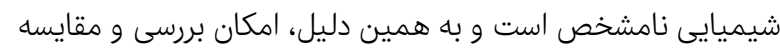

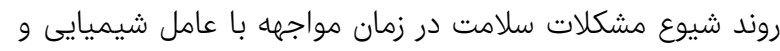

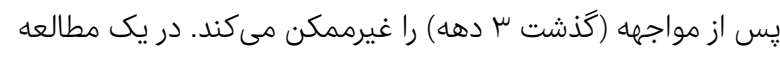

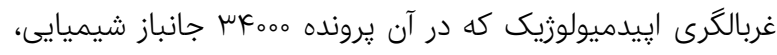

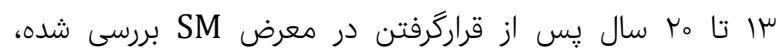

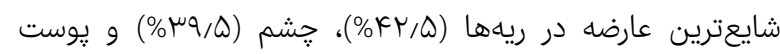

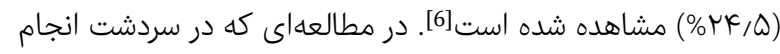

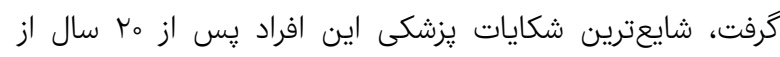

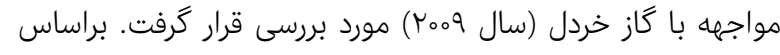

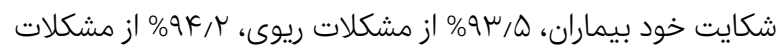

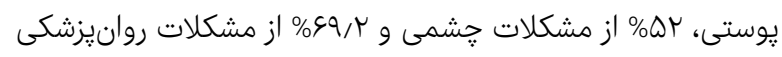

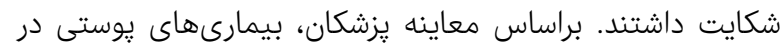

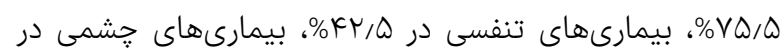

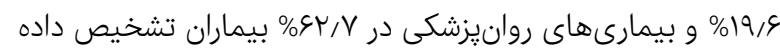

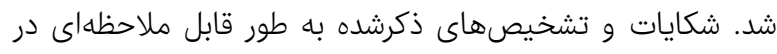

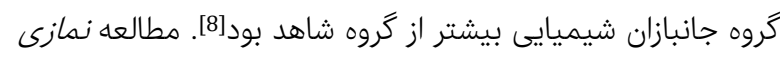

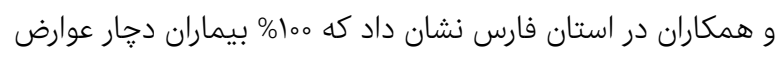

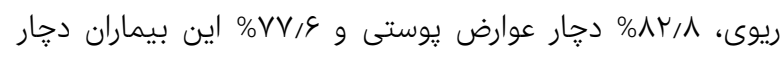
عوارض קشمى بودند [9].

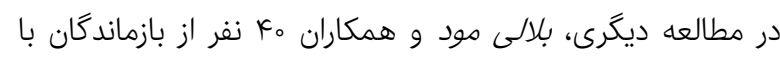

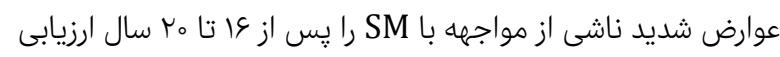

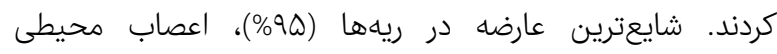

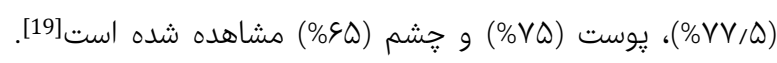
زوجاجى و همكاران در بررسى خود نشان دادند كه به غيراز مشكلات

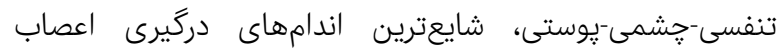

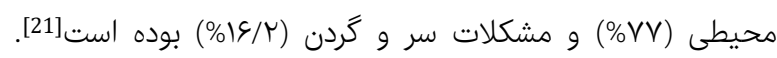

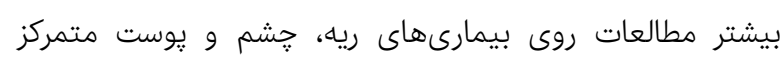

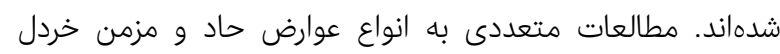

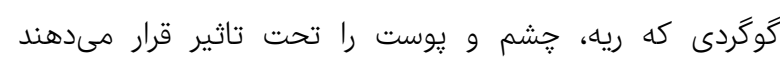

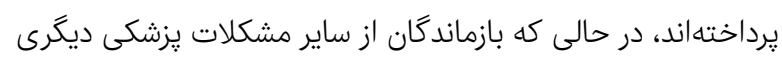

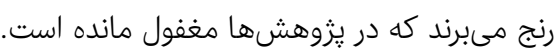

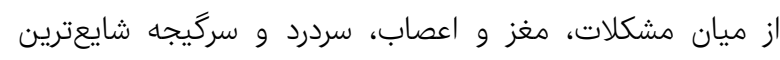

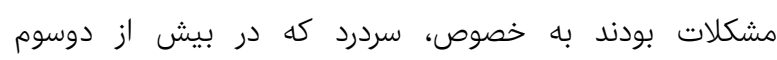

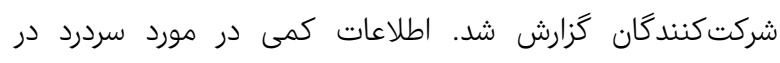

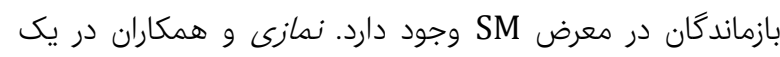

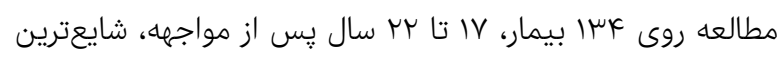

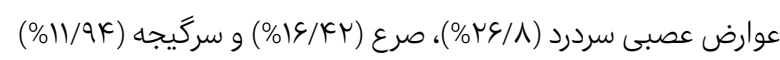

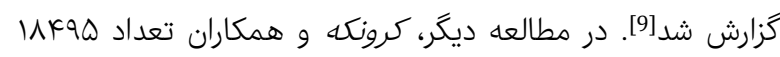

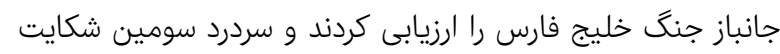

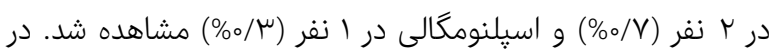

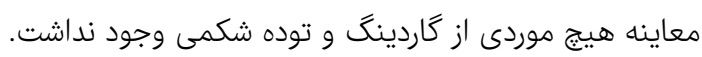

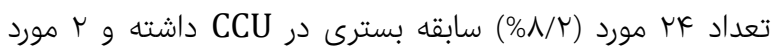
تحت جراحى باىيس عروق كرونرى قلب قرار گرفته بودند.

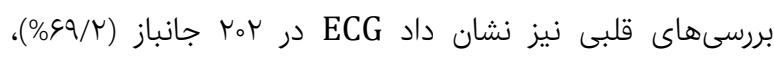

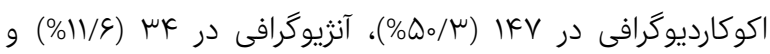

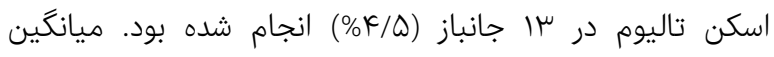

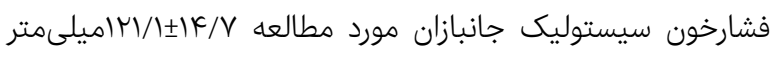

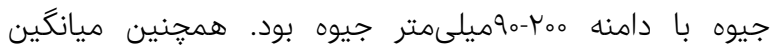

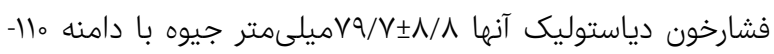

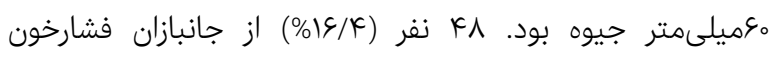

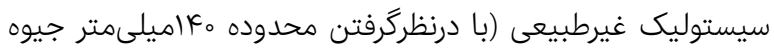

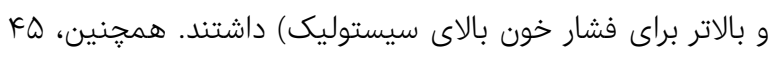

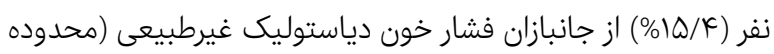

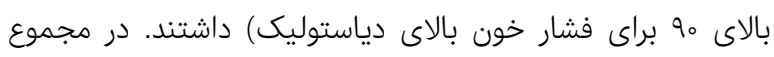

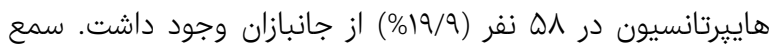

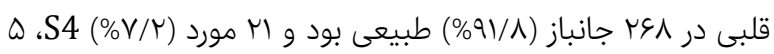

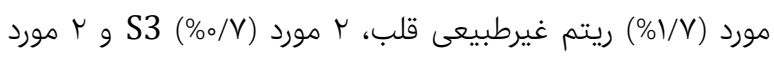

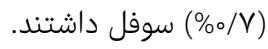

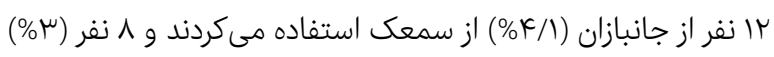

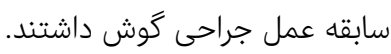

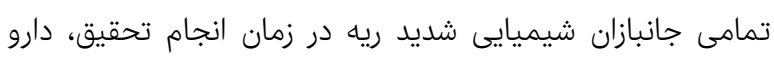
مصرف مىكردند. داروهاى مصرفى عبارت از برنكوديلاتورها، كورتيكو

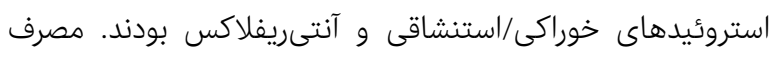

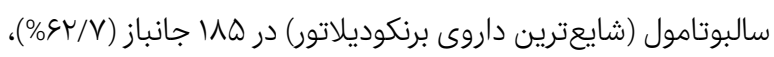

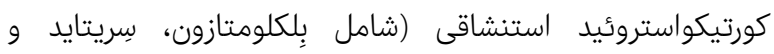

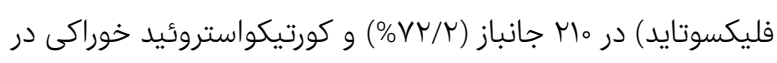

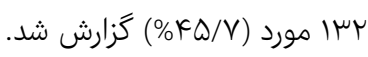

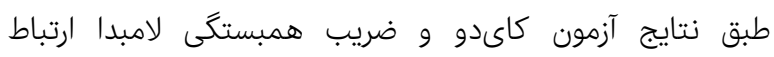
معنىدارى بين جنس، سن، دفعات مواجها با خردل گوگردى با شيوع شكايتهاى جسمى و بيمارىهاى اسكلتى-عضلانى، سيستم عصبى، دستخاه گَارش، سيستم قلبى-عروقى و شنوايى مشاهده نشد (p>o/。).

\section{بحث}

اطلاعات كمى در مورد شيوع بيمارىهاى مزمن از جمله مشكلات

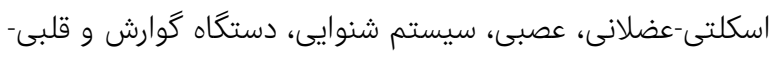

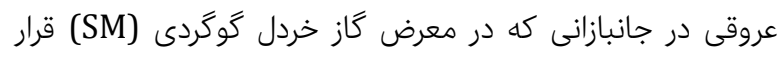

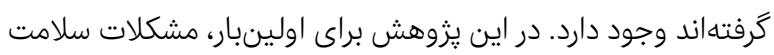

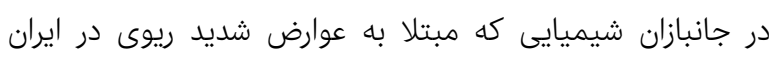

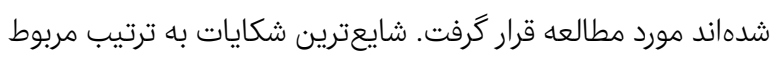

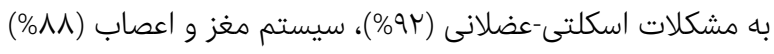

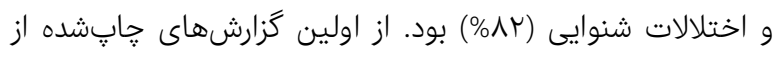
عوارض شيميايى ناشى از اثرات مواجهه با SM كه در عسب آنس جانباز 


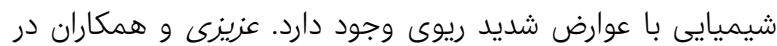
مطالعه شمارش اسيرم كه در جانبازان شيميايى مرد در سالهاي

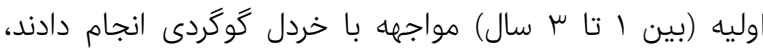

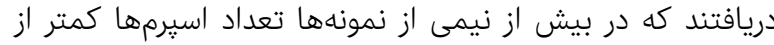

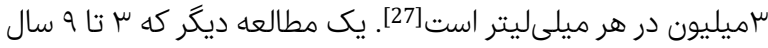

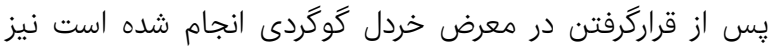

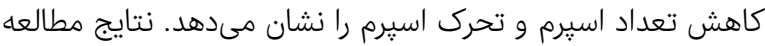

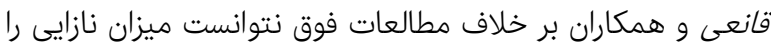

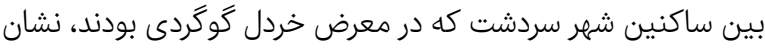

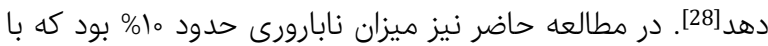
يافتهاى قانعى و همكاران هم خوانى بيشترى دارد. نتايج مطالعات

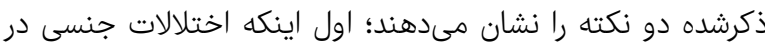
جانبازان شيميايى شديد ريه بسيار شايع است و نكته دون دوم، اينكان اينكه

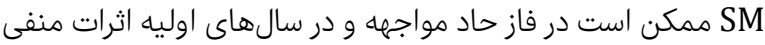

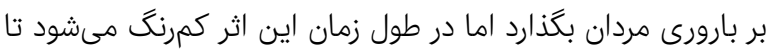

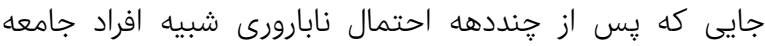

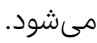
مصرف بالاى كورتيكواستروئيد در بيش از دوسوم جانبازان دو دوري

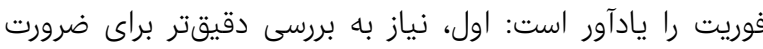

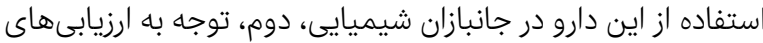
تشخيصى و بالينى در خصوص عوارض ناشى از مصرف كورتون.

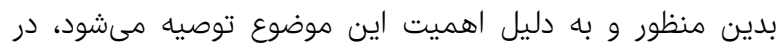

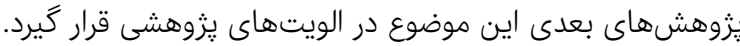
از جمله محدوديتها اين بود كه جامعه مورد مطالعه، اكثرا مردان

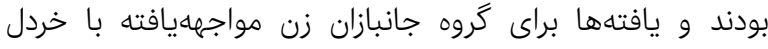

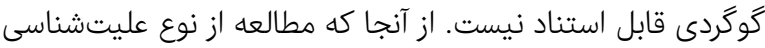

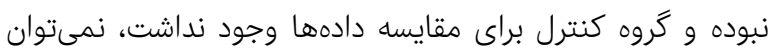

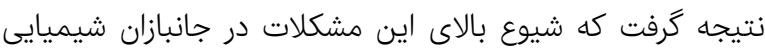

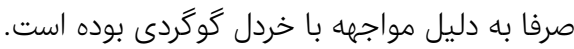

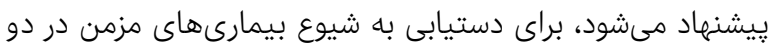

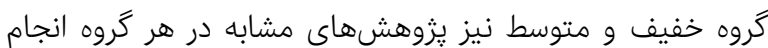
شود و همجنين، مطالعات بيشترى با كروه كنترل براى اثبات آن كفروان

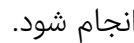

\section{نتيجه}

مشكلات اسكلتى-عضلانى (كمردرد)، مغز و اعصاب (سردرد مزمن)،

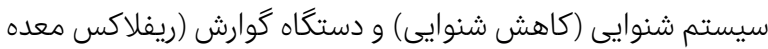

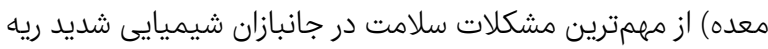

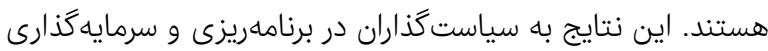
درست بهمنظور ارتقاى سطح سلامت جانبازان شيميايى مبتلا به به عوارض شديد ريه كمك مىكند. تشكر و قدردانى: نويسندكان مراتب تشكر و قدردانى خود را از آقاى دكتر

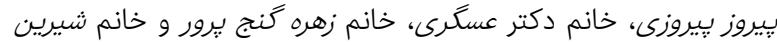

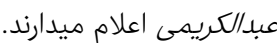

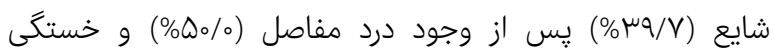

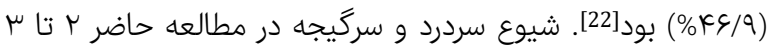
برابر مطالعات مشابه بود، هرجند شيوع بيمارد

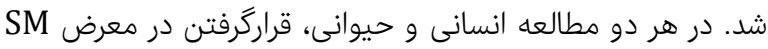

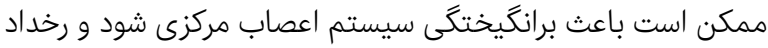
مشكلات ناشى از آن را توجيه مى كند. علاوه بر ائن اين، در جنَّ جهانى

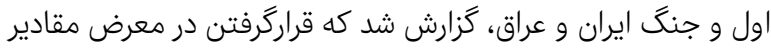

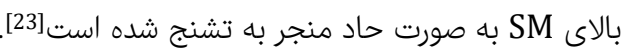
مشكلات دستكاه گوارش در اكثر شركت كنندكان مشاهدان

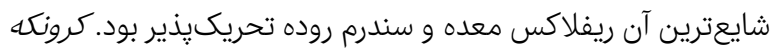

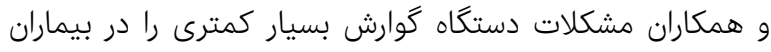

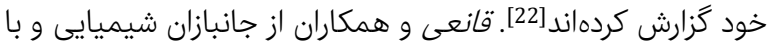

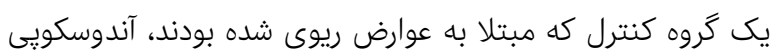

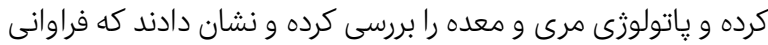

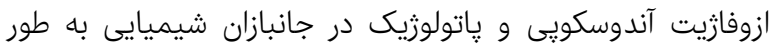

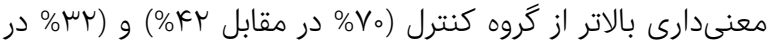

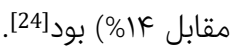
نتايج مطالعه حاضر همسو در تاييد يافتههاى فوق است و مى دوتوان نتيجه كَرفت كه شيوع ريفلاكس معده در بيماران در معرض عوامل شيميايى در مقايسه با جمعيت عادى بيشتر است؛ هرجئن

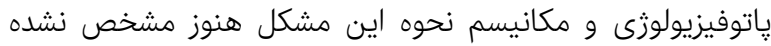

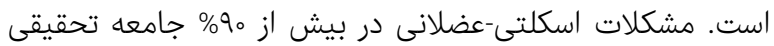

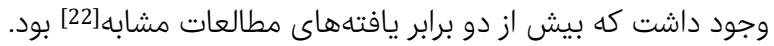

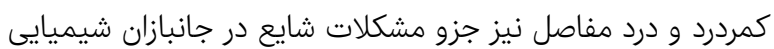

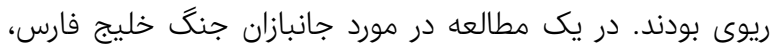

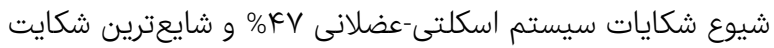

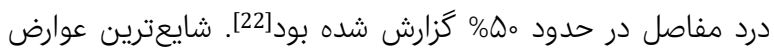

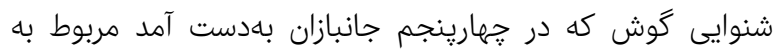

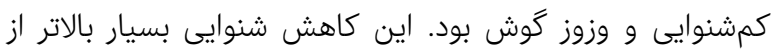
جمعيت عادى، حتى بيشتر از جمعيت سالخورده (

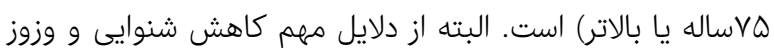

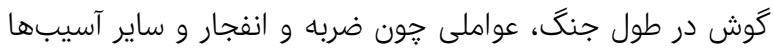
ارنش دارند از اين رو اين نتايج نمىتوانند اثرات مستقيم

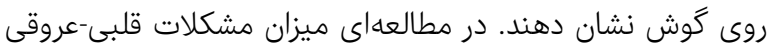
مشاهدهشده از يافتههاى مطالعه حاضر بالاتر بود

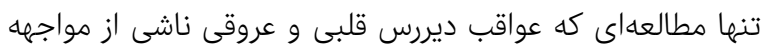
با خردل گَوگردى را ارزيابى كرده، مطالعه غلامرضا نثزاد و همكاران

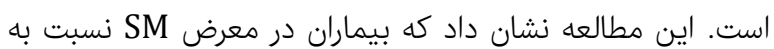

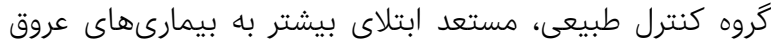

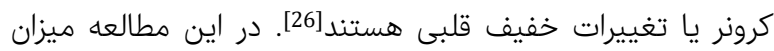

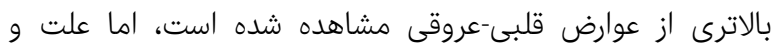

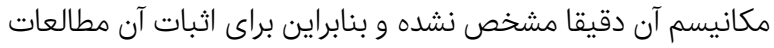

$$
\text { بيشترى لازم است. }
$$

مطالعات محدودى در مورد ناباورى و مشكلات جنسى در جانبازان 
and the relationship with respiratory and cutaneous complications. Clin Exp Ophthalmol. 2006;34(4):342-6. 13- Ghasemi H, Ghazanfari T, Babaei M, Soroush MR, Yaraee R, Ghassemi-Broumand M, et al. Long-term ocular complications of sulfur mustard in the civilian victims of Sardasht, Iran. Cutan Ocula Toxicol. 2008;27(4):317-26. 14- Ghasemi H, Ghazanfari T, Yaraee R, Soroush MR, Ghassemi-Broumand M, Poorfarzam S, et al. Systemic and ocular complications of sulfur mustard: A panoramic review. Toxin Rev. 2009;28(1):14-23.

15- Ghassemi-Broumand M, Agin K, Kangari H. The delayed ocular and pulmonary complications of mustard gas. J Toxicol Cutan Ocul Toxicol. 2004;23(4):293-302.

16- Ghassemi-Broumand M, Aslani J, Emadi S-N. Delayed ocular, pulmonary, and cutaneous complications of mustards in patients in the city of Sardasht, Iran. Cutan Ocul Toxicol. 2008;27(4):295-305.

17- Soroush MR, Ghanei M, Assari S, Khoddami Vishteh HR. Urogenital history in veterans exposed to high-dose sulfur mustard: A preliminary study of self-reported data. Urology Journal. 2009;6(2):114-19.

18- Shohrati M, Davoudi M, Ghanei M, Peyman M, Peyman A. Cutaneous and ocular late complications of sulfur mustard in Iranian veterans. Cutan Ocul Toxicol. 2007;26(2):73-81.

19- Balali-Mood M, Hefazi M, Mahmoudi M, Jalali E, Attaran D, Maleki M, et al. Long-term complications of sulphur mustard poisoning in severely intoxicated Iranian veterans. Fundam Clin Pharmacol. 2005;19:71321.

20- Balali-Mood M, Hefazi M. The clinical toxicology of sulfur mustard. Arch Iran Med. 2005;8(3):162-79.

21- Zojaji R, Balali-Mood M, Mirzadeh M, Saffari A, Maleki M. Delayed head and neck complications of sulphur mustard poisoning in Iranian veterans. J Laryngol Otol. 2009;123(10):1150-54.

22- Kroenke K, Koslowe P, Roy M. Symptoms in 18,495 Persian Gulf War veterans: latency of onset and lack of association with self-reported exposures. J Occup Environ Med. 1998;40(6):520-8.

23- Somani Satu M, Lukey BJ, Romano Jr. JA, Romano JA, Salem H, editors. Chemical warfare agents: Toxicity at low levels. Boca Raton: CRC Press; 2001. pp. 245-60.

24- Ghanei M, Khedmat H, Mardi F, Hosseini A. Distal esophagitis in patients with mustard gas induced chronic cough. Dis Esophagus. 2006;19(4):285-8.

25- Eisen SA, Kang HK, Murphy FM, Blanchard MS, Reda DJ, Henderson WG, et al. Gulf War veterans' health: Medical evaluation of a US cohort. Ann Intern Med. 2005;142(11): 881-90.

26- Gholamrezanezhad A, Saghari M, Vakili A, Mirpour S, Farahani MH. Myocardial perfusion abnormalities in chemical warfare patients intoxicated with mustard gas. Int J Cardiovasc Imaging. 2007;23(2):197-205.

27- Azizi F, Keshavarz A, Roshanzamir F, Nafarabadi M. Reproductive function in men following exposure to chemical warfare with sulphur mustard. Med War. 1995;11(1):34-44.

28- Ghanei M, Rajaee M, Khateri S, Alaeddini F, Haines D. Assessment of fertility among mustard-exposed residents of Sardasht, Iran: A historical cohort study. Reprod Toxicol. 2004;18(5):635-9.

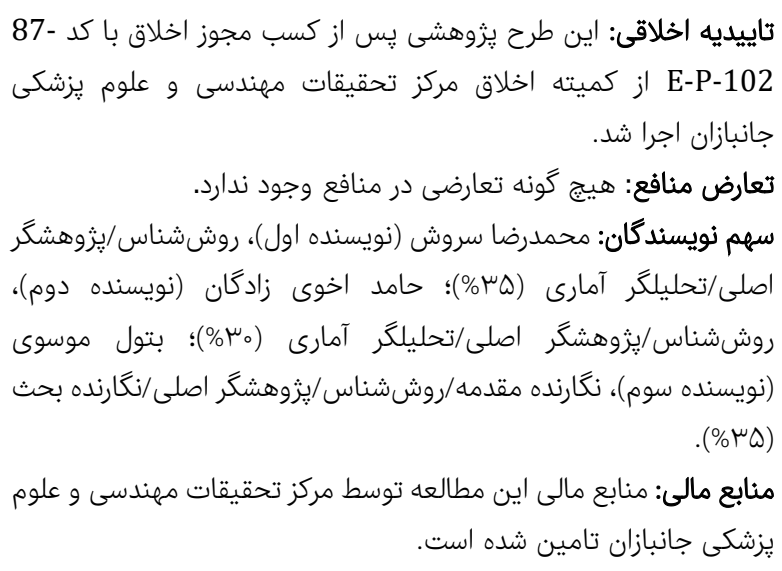

منابع

1- Marrs TT, Maynard RL, Sidell F, editors. Chemical warfare agents: Toxicology and treatment. $2^{\text {nd }}$ Edition. New Jersey: John Wiley \& Sons, Inc; 2007.

2- Taebi Gh, Soroush MR, Modirian E, Khateri S, Mousavi B, Ganjparvar Z, et al. Human Costs of Iraq's chemical war against Iran; an epidemiological study. Iran J War Public Health. 2015;7(2):115-21. [Persian]

3- Saladi R, Smith E, Persaud AN. Mustard: A potential agent of chemical warfare and terrorism. Clin Exp Dermatol. 2006;31(1):1-5.

4- Somani SM, Romano Jr JA, Romano JA, Salem H, Lukey BJ. Chemical warfare agents: Toxicity at low levels. $1^{\text {st }}$ Edition. Florida: CRC Press; 2000.

5- Balali Mood M, Hefazi M. Comparison of early and late toxic effects of sulfur mustard in Iranian veterans. Basic Clin Pharmacol Toxicol. 2006;99(4):273-82.

6- Khateri S, Ghanei M, Keshavarz S, Soroush M, Haines D. Incidence of lung, eye, and skin lesions as late complications in 34,000 Iranians with wartime exposure to mustard agent. J Occup Environ Med. 2003;45(11):1136-43.

7- Emad A, Rezaian GR. The diversity of the effects of sulfur mustard gas inhalation on respiratory system 10 years after a single, heavy exposure analysis of 197 cases. Chest.1997;112(3):734-8.

8- Moaiedmohseni S, Ghazanfari T, Araghizadeh H, Soroush MR, Yaraee R, Hassan ZM, et al. Long-term health status 20 years after sulfur mustard exposure. Toxin Rev. 2009;28(1):3-7.

9- Namazi S, Niknahad H, Razmkhah H. Long-term complications of sulphur mustard poisoning in intoxicated Iranian veterans. J Med Toxicol. 2009;5(4):191-5.

10- Panahi Y, Naderi M, Zare MA, Poursaleh Z. Ocular effects of sulfur mustard. Iran J Ophthalmol. 2013;25(2):90-106. [Persian]

11- Hejazi S, Soroush MR, Moradi A, Khalilazar S, Mousavi B, Firooz A, et al. Skin manifestations in sulfur mustard exposed victims with ophthalmologic complications: Association between early and late phase. Toxicol Reports. 2016;3:679-84.

12- Etezad-Razavi M, Mahmoudi M, Hefazi M, Balali-Mood M. Delayed ocular complications of mustard gas poisoning 